\title{
Beverage milk consumption patterns in the United States: Who is substituting from dairy to plant-based beverages?
}

\author{
Christopher A. Wolf, ${ }^{1 *}$ (1) Trey Malone,${ }^{2}$ and Brandon R. McFadden ${ }^{3}$ \\ ${ }^{1}$ Charles H. Dyson School of Applied Economics and Management, Cornell University, Ithaca, NY 14853 \\ ${ }^{2}$ Department of Agricultural, Food, and Resource Economics, Michigan State University, East Lansing 48824 \\ ${ }^{3}$ Department of Applied Economics and Statistics, University of Delaware, Newark 19716
}

\section{ABSTRACT}

This research used a survey of 995 US households to explore how dairy milk and plant-based beverage substitutes were consumed. Long-term trends of declining beverage milk consumption have been exacerbated in recent years by increasing consumption of plant-based beverages. Although beverage milk consumption has been declining, total dairy consumption in the United States continues to increase, driven by growth in sales of cheese, butter, and yogurt. Using $k$-means cluster analysis, 3 consumption clusters for US households were identified. The largest cluster, consisting of $61.6 \%$ of households, consumed dairy milk with some regularity and consumed little or no plant-based beverages. A second cluster, flexitarian households, consisting of $15.6 \%$ of respondent households, frequently consumed both dairy milk and plant-based beverages. The third cluster, plant-based consumers, consisting of $22.8 \%$ of households, consumed almost exclusively plant-based beverages. Examining differences in demographics between clusters, flexitarian households were larger, more likely to include young children, more likely to include a vegetarian or vegan, and more liberal than traditional dairy-consuming households. Plant-based households had many similarities to flexitarian households. The flexitarian and plant-based clusters were willing to substitute plant-based beverages for dairy milk for almost all consumption uses.

Key words: beverage milk, consumer demand, market segment, plant-based beverage

\section{INTRODUCTION}

Consumers in the United States have long viewed dairy milk as a foundation to a healthy diet, from complementing cold cereal and coffee to school lunch

Received April 18, 2020.

Accepted August 8, 2020.

*Corresponding author: cwolf@cornell.edu programs. Federal nutrition policy and dairy industry promotions alike have long recognized milk as a high-quality source of protein and calcium, and-more recently - as a source of high-quality fat (ChalupaKrebzdak et al., 2018). Although dairy milk has a long history as a food staple, fluid milk sales revenues in the United States decreased from almost $\$ 19$ billion in 2013 to less than $\$ 16$ billion in 2018, with little optimism for future growth (Mintel, 2018). Nevertheless, total dairy product consumption has increased through growth in sales of cheese, yogurt, butter, and other dairy products.

Some of the decline in beverage milk consumption has been due to substitution with plant-based alternative beverages made from soybeans, almonds, and other nut and grain crops. Nondairy alternatives have grown by $61 \%$ since 2013 , and retail sales reached $\$ 2.3$ billion in 2018 (Mintel, 2018). The transition to plant-based beverages by some consumers has significant implications for dairy product marketing and policy, motivating advocacy groups to propose legislation that might prevent nondairy alternatives from using the word "milk" on packaging and marketing (Irfan, 2018). Empirical evidence of actual consumer confusion caused by plant-based beverages labeled as "milk" is largely mixed (NMPF, 2019; Whitmer, 2019), suggesting that more research is needed to understand the degree of confusion and its influence on choice.

Despite extensive research on the role of consumer heterogeneity in dairy consumption, few studies have included plant-based alternatives in market segmentation analyses. Even fewer studies have investigated differences in substitution effects across differing uses of milk (e.g., in coffee or on cereal). Instead, prior research has either evaluated market segments of fluid milk (Harwood and Drake, 2018) or considered the motivations that might influence consumers to choose plantbased alternatives (McCarthy et al., 2017). Some studies that have compared perceptions of nutrition content in dairy milk and milk alternatives in other countries, such as Australia (Bus and Worsley, 2003a,b), Canada 
(Préjet, 2018), and Turkey (Atabek and Atabek, 2019), suggest that significant confusion exists in consumer perceptions. In the United States, studies have focused on milk production attributes (Wolf et al., 2011) and consumer segmentation within dairy milk (Bir et al., 2019), finding that consumers are willing to pay significant amounts for aspects including fat content. Perhaps most relevant for this study are the findings of Finnell and John (2017), who examined consumption of low-fat and high-fat milk. Focusing on US recipients of nutrition assistance, Finnell and John (2017) found that less low-fat milk consumption was associated with a knowledge gap and misperceptions of the nutritional properties of the different types of milk.

This study uses primary data from 995 households in the United States to explore market segments of dairy and nondairy milk consumers. By comparing these market segments, this research contributes to the literature by determining differences in demographics of households and identifies substitution effects across differing uses based on patterns of dairy and plant-based beverage consumption.

\section{MATERIALS AND METHODS}

\section{US Dairy Milk Consumption Trends}

To understand the context and background of milk consumption patterns in the United States, statistics from the US Department of Agriculture Economic Research Service (USDA ERS, 2020) were used. Trends in per capita consumption of beverage milk, cheese, and butter, per capita consumption by fluid milk type, and total US commercial disappearance are examined over time and implications are discussed.

\section{US Household Survey}

The US public survey was written by a team of Michigan State University, Cornell University, and University of Delaware researchers in January 2019. The survey was anonymous and approved by Michigan State University's Human Research Protection Program. Prior to implementation, the survey instrument was piloted on Amazon's Mechanical Turk (M-Turk; Amazon, Seattle, WA) platform. The survey was implemented during March 2019 in collaboration with SSI-Dynata (Plano, TX), who maintain a panel of representative US food households. To participate in the survey, respondents must be $21 \mathrm{yr}$ of age. Respondents were not compensated for participating. The survey took the average respondent about $15 \mathrm{~min}$. A total of 995 completed surveys were collected for this study.
The national online survey collected information about US public milk consumption patterns, willingness to substitute alternatives for dairy milk, and demographic characteristics, including age, education, sex, household size, and income. Consumption patterns are one key question regarding the substitutability of dairy milk and nondairy alternatives. This research focused on respondents who were the primary food shopper to examine household purchasing and consumption preferences.

\section{k-Means Cluster Analysis}

From the consumption pattern questions, $k$-means cluster analysis was conducted as it is commonly used to identify market segments based on consumer survey responses. Prior studies have used this method to analyze markets such as the craft beer market (Malone and Lusk, 2018) and contract design in the dairy industry (Schlecht and Spiller, 2012). From these identified clusters, demographics and substitution patterns were compared.

Clustering refers to the grouping of a set of respondents based on their characteristics, aggregating them according to their similarities. $k$-Means clustering partitions $n$ observations into $k$ clusters in which each observation belongs to the cluster with the nearest mean. In this research, the clusters were based on responses to a series of questions about beverage consumption by the household. The products examined included 6 dairy milks (skim milk, $1 \%$ milk, $2 \%$ milk, whole milk, chocolate milk, and lactose-free milk) and 5 plant-based beverages (almond milk, soy milk, cashew milk, other nut milks, and other grain milks). For each of 11 products, respondents were asked, "How would you describe your consumption of the following products?" Potential responses included the following: $1=$ regular part of my diet; $2=$ consume, but not on a regular basis; 3 $=$ limit my consumption; $4=$ don't consume at all. Respondents were assigned to each cluster iteratively until the distance between each observation and the center of the cluster or centroid was minimal. Three $k$ means milk consumption clusters were estimated using the "cluster kmeans" command in Stata 16 (StataCorp LLC, College Station, TX).

\section{Statistical Analysis Across Clusters}

Summary statistics, including means and standard deviations, were used to describe the quantitative questions. Many of the questions were asked with a Likert scale response such as $1=$ very likely, $2=$ likely, $3=$ somewhat likely, $4=$ unlikely, $5=$ very unlikely, and 
$6=$ never. To compare sociodemographics and choices across consumption clusters, Welch's t-tests assuming unequal variances were calculated using Microsoft Excel (Microsoft Corp., Redmond, WA). Welch's $t$-test was used because the clusters had unequal sizes and unequal variance.

Respondents were also asked whether they would be likely to substitute a plant-based alternative for milk in uses including as a beverage, in coffee, on cereal, in a smoothie, as a cooking ingredient, in desserts, for kids, and for pets. Comparing $t$-tests for these responses revealed substitution patterns by household cluster.

\section{RESULTS AND DISCUSSION}

\section{US Dairy Consumption Trends}

Figure 1 displays per capita consumption of beverage dairy milk, cheese, and butter from 1975 through 2018. Beverage milk consumption trended downward on a per capita basis consistently between 1975 and 2018 . Between 1975 and 2018, per capita beverage milk consumption declined $41 \%$ from $50.8 \mathrm{~kg} /$ person to $30 \mathrm{~kg} /$ person. Beverage consumption per capita declined $26 \%$ from 2000 to 2018 and $18 \%$ from 2010 to 2018. The downward trend has been attributed to declining milk consumption frequency rather than changing serving portions (Stewart et al., 2013). Americans born in the 1990s consume milk less often than earlier generations (Capps et al., 2016). This trend is particularly concerning for industry growth: as younger generations replace older ones, the average level of fluid milk consumption may continue to decline (Stewart et al., 2013).

In contrast to beverage consumption, cheese consumption per capita increased consistently from 1975 to 2018 . From 1975 to 2018 the increase totaled $177 \%$, from $6.5 \mathrm{~kg} /$ person to $17.9 \mathrm{~kg} /$ person. Cheese consumption per capita increased 34\% from 2000 to 2018 and $20.6 \%$ from 2010 to 2018 . This increase occurred across all types of cheese and reflected changing patterns of consumption away from home, particularly on pizza.

Over the same period, butter consumption per capita increased $23 \%$ from 1975 to 2018, going from 2.14 to $2.63 \mathrm{~kg} /$ person. However, per capita consumption of butter fluctuated around $2.0 \mathrm{~kg} /$ person for the first 25 yr of that period. In the 1980s there was a great deal of bad press about the health implications of animal fat consumption. Recent years have witnessed a reversal of the health views of butterfat and have driven a per capita increase of $18 \%$ since 2010 from $2.23 \mathrm{~kg} /$ person to $2.63 \mathrm{~kg} /$ person.

Figure 2 displays US per capita total dairy product consumption on a milk equivalents milkfat basis. Total dairy product consumption per capita has increased over the 1975 to 2018 time period. In the 1980s, many leading health authorities promoted a diet with minimal animal fat consumption (Teicholz, 2014). In 1975, Americans consumed $244.5 \mathrm{~kg}$ of milk-equivalent dairy products per person, which increased $48.4 \mathrm{~kg}$ to 292.9 $\mathrm{kg} /$ person by 2018. Total US per capita dairy product consumption increased $25.5 \%$ since 2000 and $9.4 \%$ since 2010. Thus, although beverage milk consumption per

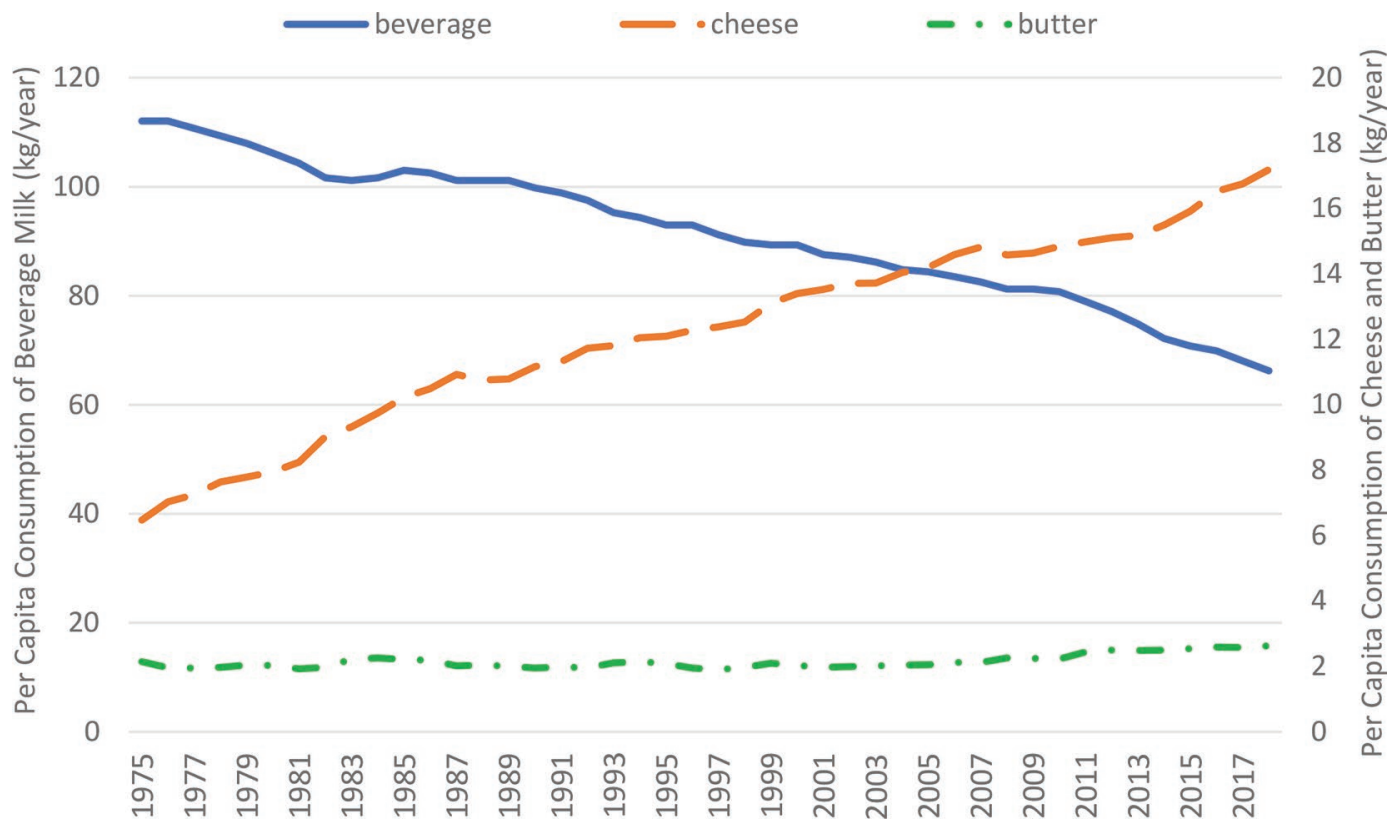

Figure 1. Per capita consumption of dairy products in the United States, 1975-2018. Data source: USDA ERS (2020). 
capita has been declining, total dairy product consumption per capita has been growing as other products including cheese, butter, and yogurt have grown.

Figure 3 displays dairy milk consumption by type, including whole, $2 \%$ milkfat (reduced fat), $1 \%$ milkfat (low fat), and skim milk, from 1975 to 2018. In contrast to the previous figures, Figure 3 is total US consumption encompassing both changes in population and per capita consumption. Over the entire period whole milk consumption declined $56 \%$, whereas consumption of $2 \%$ milk $(+80 \%), 1 \%$ milk $(+138 \%)$, and skim milk $(62 \%)$ all increased. However, examining the entire $43-y r$ period obscures recent trends. From 1975 to 1995, whole milk consumption declined precipitously while total consumption of types-particularly $2 \%$ milk-grew. Since the mid 1990s, only 1\% (low-fat) milk total consumption consistently increased. More recently, whole milk consumption grew $15.3 \%$ from 2013 to 2018; this was the only category of milk consumption to increase.

\section{Survey Summary Statistics}

Summary statistics of respondent demographics are provided in Table 1 . As the survey was aimed at the primary shopper, respondents were $58 \%$ female compared with the actual $51 \%$ of Americans that were female (US Census Bureau, 2018). Average household size was about 2.5 people, slightly smaller than the US Census reported for the general population of 2.7 people. The average age of respondents was $44.9 \mathrm{yr}$. The median age of survey respondents was $49 \mathrm{yr}$ compared with a US median age of 37 yr (US Census Bureau, 2018). Respondent formal educational level was higher than the US average, with the average respondent having some college or vocational training beyond high school. Respondent households had annual incomes averaging $\$ 55,779$. For comparison, the median US household income was $\$ 53,046$ (US Census Bureau, 2018). Thus, the respondent sample was on average older, more educated, and more likely to be female than the US population in general but spanned a broad range of all those demographics.

About $24 \%$ of respondents had children under $12 \mathrm{yr}$ in their household. Almost 10\% indicated that at least 1 person in the household was a vegetarian or vegan. About one-sixth of respondents stated they were currently on a diet. About $32 \%$ of respondent households had received nutritional or food assistance (i.e., food stamps). Respondents were also asked whether they identified as liberal, moderate, or conservative or did not know. About one-third of respondents identified as liberal.

\section{Milk Consumption Cluster Types}

Table 2 presents the results from the $k$-means cluster analysis, which were calculated based on responses to versions of the question "How would you describe your consumption on the following products?" Three clusters of households consuming dairy and nondairy beverages were identified. "Dairy households" comprised $61.6 \%$ of the respondent sample. This cluster of respondent

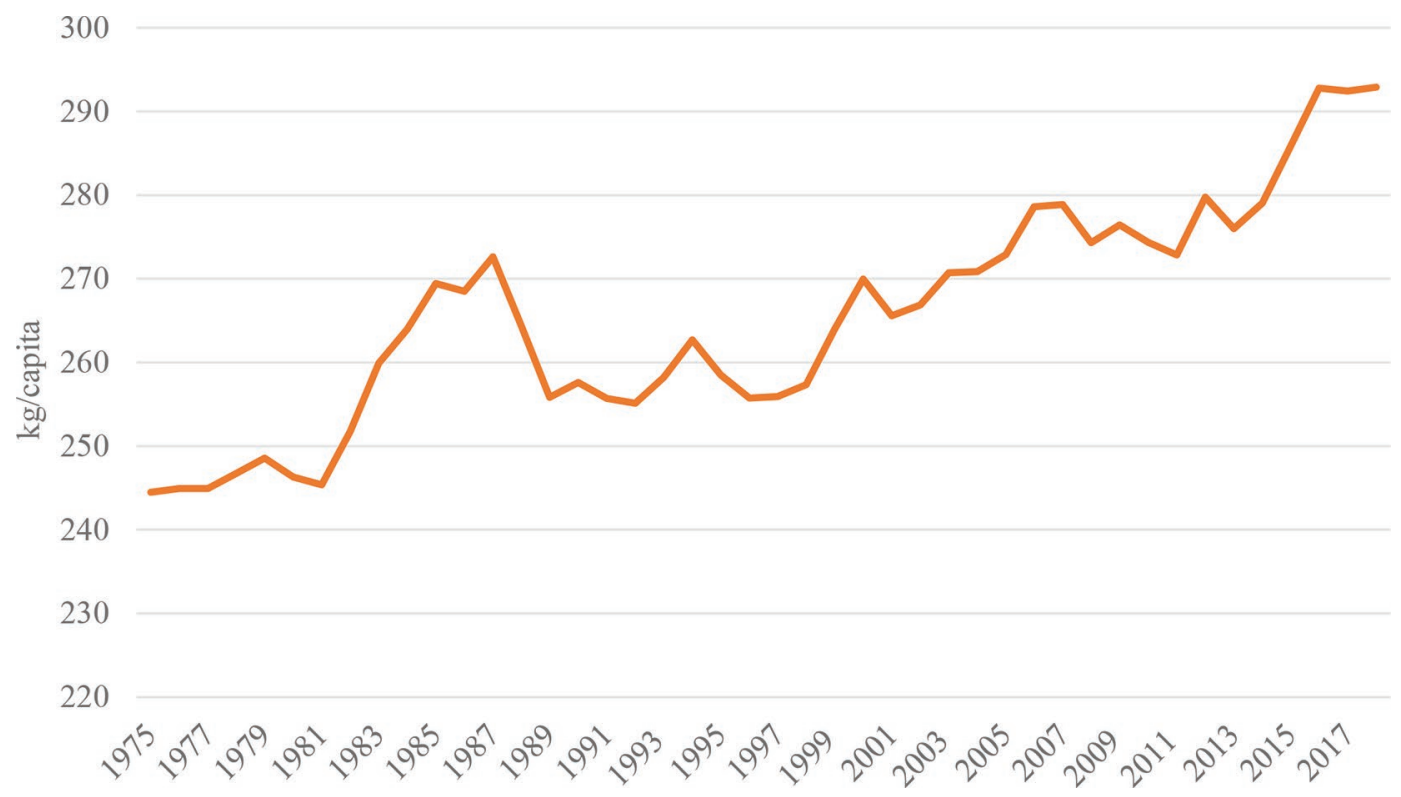

Figure 2. Per capita total dairy product consumption in the United States, milk equivalents milkfat basis. Data source: USDA ERS (2020). 
Table 1. Demographics (mean; SD in parentheses) of all respondents $(\mathrm{n}=995)$

\begin{tabular}{|c|c|c|}
\hline Variable & Unit & All respondents \\
\hline Age & yr & $44.9(16.4)$ \\
\hline Sex & $\%$ female & $58.4(49.3)$ \\
\hline Education & yr & $14.2(2.4)$ \\
\hline Annual household income & $\$$ & $55,779(38,699)$ \\
\hline Household primary food shopper & $\%$ yes & $75.0(43.3)$ \\
\hline People in household & no. & $2.5(1.2)$ \\
\hline Children under age $12 \mathrm{yr}$ in household & $\%$ yes & $23.9(42.7)$ \\
\hline Vegetarian or vegan household & $\%$ yes & $9.5(29.3)$ \\
\hline Currently following a diet & $\%$ yes & $16.4(37.0)$ \\
\hline Have ever received food stamps or supplemental nutrition assistance & $\%$ yes & $32.3(46.8)$ \\
\hline Political affiliation ${ }^{1}$ & $\%$ liberal & $32.0(46.7)$ \\
\hline
\end{tabular}

"Liberal" indicates respondent answered extremely or slightly liberal as opposed to moderate, slightly conservative, or extremely conservative.

households consumed dairy milk-primarily $2 \%$ and whole milk - on a somewhat regular basis and had limited to no consumption of other milks and plant-based beverages. As the majority cluster, dairy households were consistent with what would be considered traditional dairy consumers. The second cluster, "flexitarian households," comprised $15.6 \%$ of the respondent households. Flexitarians consumed all types of dairy and plant-based milk. The median flexitarian consumed $2 \%$ and $1 \%$ dairy milk the most but also consumed all types of the beverages examined with at least some regularity. The third cluster, "plant-based households," comprised $22.8 \%$ of respondent households. Plant-based households frequently consumed almond milk and little else.
These market clusters suggest that more than threefourths of the respondent households consumed dairy milk with at least some regularity. The flexitarian household cluster had very similar mean responses to the consumption of all types of milk beverages but constituted only about one-sixth of respondents. The plant-based household consumption cluster was almost exclusively almond beverage drinkers. Almond milk is the most popular plant-based milk substitute beverage but recently has been criticized for water use and lack of nutrients (Naylor, 2018). It is entirely possible that consumers seeking to primarily drink plant-based beverages will change types as different factors and perceptions related to nutrition and environmental impact come to light.

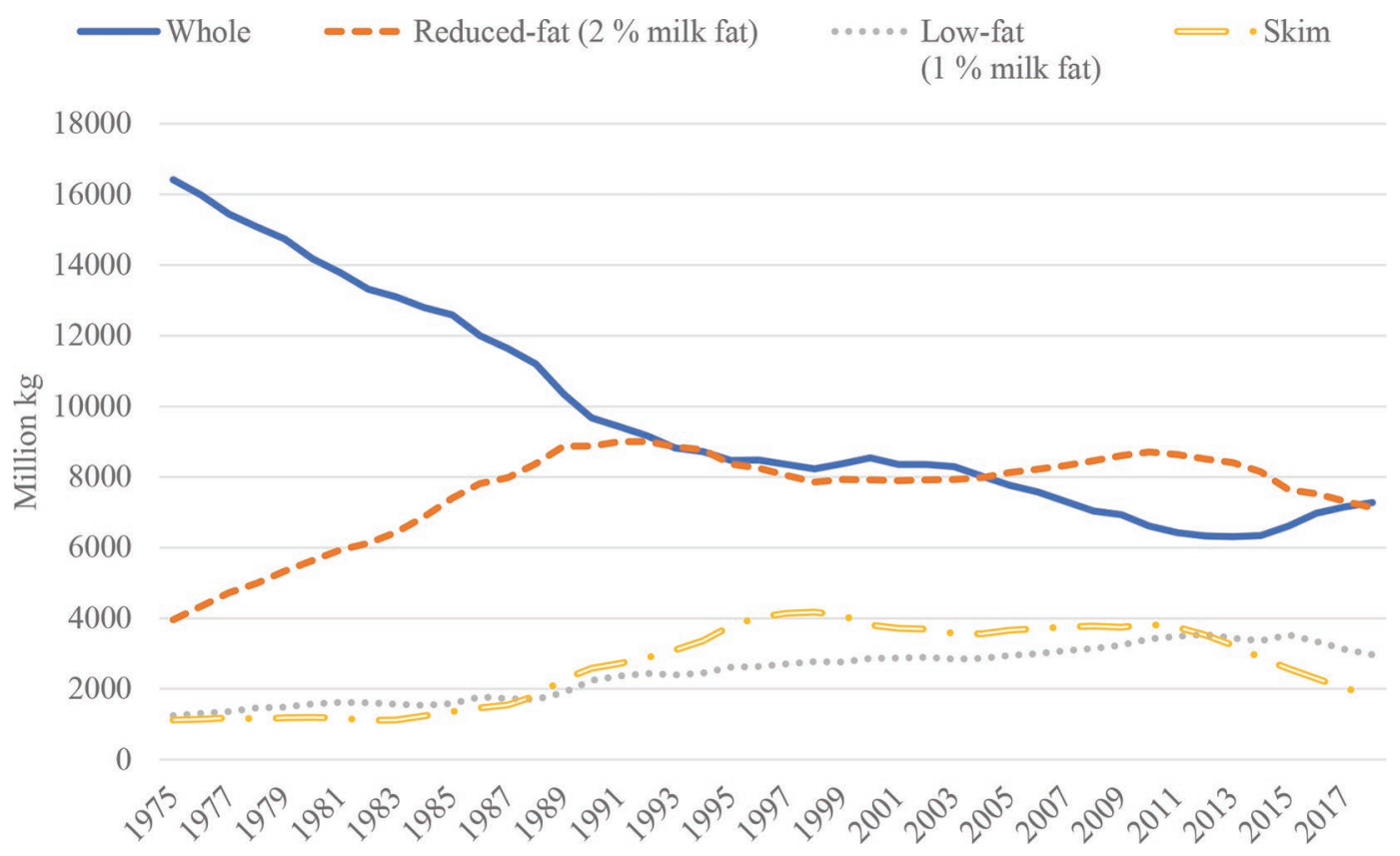

Figure 3. Total US dairy milk consumption by type, 1975-2018. Data source: USDA ERS (2020). 
Table 2. $k$-Means clusters (SD in parentheses) of consumers of dairy and plant-based beverages

\begin{tabular}{lccc}
\hline & \multicolumn{3}{c}{ Consumer cluster } \\
\cline { 2 - 4 } Item & Dairy & Flexitarian & Plant-based \\
\hline No. & \multicolumn{2}{c}{155} & 227 \\
Dairy & $3.39(1.03)$ & $2.16(0.96)$ & $3.56(0.82)$ \\
Skim milk & $3.29(1.00)$ & $1.92(0.86)$ & $3.59(0.72)$ \\
$1 \%$ milk & $2.43(1.20)$ & $1.68(0.77)$ & $2.90(1.15)$ \\
$2 \%$ milk & $2.62(1.18)$ & $2.09(0.93)$ & $2.98(1.14)$ \\
Whole milk & $3.12(0.94)$ & $2.24(0.97)$ & $3.11(0.95)$ \\
Chocolate milk & $3.85(0.60)$ & $2.42(1.06)$ & $3.64(0.79)$ \\
Lactose-free milk & & & \\
Plant-based & $3.87(0.39)$ & $2.00(0.78)$ & $1.70(0.63)$ \\
Almond milk & $3.92(0.36)$ & $2.21(0.97)$ & $3.13(1.04)$ \\
Soy milk & $3.96(0.25)$ & $2.61(1.05)$ & $3.61(0.74)$ \\
Cashew milk & $3.97(0.23)$ & $2.54(1.05)$ & $3.50(0.85)$ \\
Other nut milks & $3.97(0.23)$ & $2.67(1.03)$ & $3.81(0.54)$ \\
Other grain milks & 61.6 & 15.6 & 22.8 \\
Percentage of sample & 61.6 \\
\hline
\end{tabular}

${ }^{1}$ Average values based on responses to "How would you describe your consumption of the following products?" 1 = regular part of my diet; 2 = consume, but not on a regular basis; $3=$ limit my consumption; $4=$ don't consume at all. Total number of observations $=995$.

\section{Household Characteristics by Cluster}

Table 3 presents demographics of the 3 consumption clusters. Respondents from the dairy household market segment were older than those from the flexitarian and plant-based household segments. Flexitarian household respondents had more formal education than plantbased consumers who, in turn, had more formal education than the dairy household segment, although the absolute mean difference was small. Flexitarian households were larger than dairy-consuming households but statistically equivalent to the households of the plantbased segment. Flexitarian households were the most likely to have children under $12 \mathrm{yr}$, whereas plant and dairy households were equally likely to have younger children. Although the survey did not inquire about lactose or other dairy allergies, it is entirely possible that the presence of children increases the likelihood that those issues play a role in household milk consumption choices.

Dairy households were least likely to have a vegetarian or vegan in the household at $4.4 \%$, whereas $27 \%$ of flexitarian households and $11 \%$ of plant-based households had a vegetarian or vegan. Approximately $22 \%$ of flexitarian household respondents indicated that they were currently on a diet. This value was statistically equivalent to the percentage of plant-based respondents who indicated that they were currently following a diet and a higher percentage than the dairy-consuming households. Flexitarian and dairy-consuming households were more likely than the plant-based segment to have ever received nutritional assistance. Flexitarian household respondents were most likely to identify as liberal, followed by plant-based respondents. Dairy households were least likely to identify as liberal.

\section{Milk Substitution Patterns}

Table 4 presents substitution patterns for each consumption cluster. For the most part, dairy consumers were not open to substituting plant-based alternatives for dairy milk in any use. The most likely substitution for dairy household consumers was in a smoothie and as a cooking ingredient, but even those uses were unlikely. In contrast, flexitarian and plant-based consuming households were likely to somewhat likely to substitute for almost all uses and were statistically equivalent. Plant-based households were generally more likely to substitute in every scenario, although they were especially likely to substitute toward plant-based

Table 3. Demographics (means; SD in parentheses) of consumer clusters

\begin{tabular}{|c|c|c|c|c|}
\hline Variable & Unit & Dairy & Flexitarian & Plant-based \\
\hline Age & $\mathrm{yr}$ & $46.9^{\mathrm{a}}(16.5)$ & $39.8^{\mathrm{b}}(14.4)$ & $43.1^{\mathrm{c}}(16.5)$ \\
\hline Sex & $\%$ female & $55.5^{\mathrm{a}}(49.7)$ & $57.4^{\mathrm{a}}(49.6)$ & $67.0^{\mathrm{b}}(47.1)$ \\
\hline Education & yr & $14.1^{\mathrm{a}}(2.3)$ & $14.5^{\mathrm{b}}(2.4)$ & $14.3^{\mathrm{ab}}(2.4)$ \\
\hline Annual household income & $\$$ & $54,144^{\mathrm{a}}(38,577)$ & $61,032^{\mathrm{a}}(40,834)$ & $56,608^{\mathrm{a}}(37,333)$ \\
\hline Children under age $12 \mathrm{yr}$ in household & $\%$ yes & $19.4^{\mathrm{a}}(39.6)$ & $41.9^{\mathrm{b}}(49.5)$ & $23.8^{\mathrm{a}}(42.7)$ \\
\hline Vegetarian or vegan household & $\%$ yes & $4.4^{\mathrm{a}}(20.5)$ & $27.1^{\mathrm{b}}(44.6)$ & $11.0^{\mathrm{c}}(31.4)$ \\
\hline Currently following a diet & $\%$ yes & $14.0^{\mathrm{a}}(34.8)$ & $21.9^{\mathrm{b}}(41.5)$ & $18.9^{\mathrm{ab}}(39.3)$ \\
\hline $\begin{array}{l}\text { Have ever received food stamps or supplemental } \\
\text { nutrition assistance }\end{array}$ & $\%$ yes & $32.1^{\mathrm{ab}}(46.7)$ & $40.0^{\mathrm{a}}(49.2)$ & $27.3^{\mathrm{b}}(44.7)$ \\
\hline Political affiliation ${ }^{1}$ & $\%$ liberal & $27.9^{\mathrm{a}}(44.9)$ & $43.2^{\mathrm{b}}(49.7)$ & $35.2^{\mathrm{b}}(47.9)$ \\
\hline
\end{tabular}

${ }^{\mathrm{a}-\mathrm{c}}$ Means of clusters within a row with different superscripts differ from other clusters $(P<0.05)$.

1"Liberal" indicates respondent answered extremely or slightly liberal as opposed to moderate, slightly conservative, or extremely conservative. 
Table 4. Likelihood of substituting plant-based beverage for dairy milk by consumer cluster ${ }^{1}$

\begin{tabular}{lccc}
\hline & \multicolumn{3}{c}{ Consumer cluster } \\
\cline { 2 - 4 } Substitution case & Dairy & Flexitarian & Plant-based \\
\hline No. of observations & 613 & 155 & 227 \\
As a beverage & $4.2^{\mathrm{a}}(1.7)$ & $2.5^{\mathrm{b}}(1.4)$ & $2.6^{\mathrm{b}}(1.4)$ \\
In coffee or tea & $4.1^{\mathrm{a}}(1.7)$ & $2.5^{\mathrm{b}}(1.4)$ & $2.7^{\mathrm{b}}(1.5)$ \\
On cereal & $4.1^{\mathrm{a}}(1.9)$ & $2.2^{\mathrm{b}}(1.4)$ & $2.2^{\mathrm{b}}(1.5)$ \\
In a smoothie or shake & $3.8^{\mathrm{a}}(1.7)$ & $2.2^{\mathrm{b}}(1.3)$ & $2.2^{\mathrm{b}}(1.3)$ \\
Baking or cooking ingredient & $3.8^{\mathrm{a}}(1.7)$ & $2.4^{\mathrm{b}}(1.3)$ & $2.7^{\mathrm{b}}(1.6)$ \\
In a dessert & $3.9^{\mathrm{a}}(1.7)$ & $2.4^{\mathrm{b}}(1.3)$ & $2.6^{\mathrm{b}}(1.5)$ \\
For children & $4.1^{\mathrm{a}}(1.8)$ & $2.6^{\mathrm{b}}(1.6)$ & $2.8^{\mathrm{b}}(1.7)$ \\
For pets & $4.6^{\mathrm{a}}(1.5)$ & $3.0^{\mathrm{b}}(1.5)$ & $3.9^{\mathrm{c}}(1.7)$ \\
\hline
\end{tabular}

${ }^{\mathrm{a}-\mathrm{c}}$ Means within a row with different superscripts differ $(P<0.05)$.

${ }^{1}$ Mean values are based on responses to "How likely are you to substitute a plant-based alternative for the traditional dairy product"? 1 = very likely; $2=$ likely; $3=$ somewhat likely; $4=$ unlikely; 5 = very unlikely; and $6=\mathrm{I}$ would never substitute. Numbers in parentheses are standard deviations.

alternatives in their smoothies and on their cereal. One interesting aspect of all 3 consumption clusters was that none were open to substituting a plant-based alternative for their pets.

\section{Market and Policy Implications}

This study suggests that although beverage milk consumption has been to a degree substituted with plant-based alternatives, many plant-based drinkers have not entirely shifted their consumption behavior away from dairy milk. Indeed, about three-fourths of households regularly consumed dairy milk, whereas about $38 \%$ consumed plant-based beverages and $16 \%$ consumed both plant-based and dairy alternatives. To date, these consumption trends and the magnitude of the consumer segments substituting with plant-based beverages have led to several policy responses and initiatives. A brief discussion of these policy issues both highlights the relevance of the findings and outlines future research needs.

As noted in the Introduction, one of the more controversial policy approaches involves restricting usage of the term "milk" on labels of beverages that are plant based. Other governments in places such as Canada and the European Union already have similar laws or regulations. Further, state-level governments across the country have already passed legislation calling into question labels not only for "milk" but also for other agricultural products, including "cauliflower rice" and plant-based "meats" (Sullivan, 2018; Karlin, 2019). North Carolina was the first state, in 2018, to enact a law that may at some point in time limit what can be called milk (Mercer, 2020). Similarly, other milk labeling bills have made it to several state legislatures, including Wisconsin, Kentucky, New York, Oklahoma, Virginia, and West Virginia (Mercer, 2020).
The US Food and Drug Administration (FDA) is considering such restriction of dairy nomenclature for nondairy product lines. There is a precedent, as the US Code of Federal Regulations (US FDA, 2019) defines milk as "the lacteal secretion, practically free from colostrum, obtained by the complete milking of one or more healthy cows, which may be clarified and may be adjusted by separating part of the fat therefrom; concentrated milk, reconstituted milk, and dry whole milk. Water, in a sufficient quantity to reconstitute concentrated and dry forms, may be added." Dairy industry groups in the United States have increasingly called for the FDA to enforce this definition, alluding to consumer confusion and misinformation about plant-based beverages (US FDA, 2019). Indeed, FDA Commissioner Scott Gottlieb (2018) explained, "Because these dairy alternative products are often popularly referred to as 'milk,' we intend to look at whether parents may erroneously assume that plant-based beverages' nutritional contents are similar to those of cow's milk, despite the fact that some of these products contain only a fraction of the protein or other nutrients found in cow's milk." The popular press has become enamored with this proposed legislation, alleging that the FDA "crackdown" represents government-granted favoritism of dairy producers over "small" upstart milk-alternative companies (Sibilla, 2019). This case is likely to have significant implications for future labeling legislation throughout food and agriculture, as the Code of Federal Regulations describes almost 300 standards of identity (Gottlieb, 2018).

Regulatory policies are not necessarily a panacea for the dairy industry, and at least some people are concerned about constitutional violations that might occur from these attempted laws (Sibilla, 2019). Intervening in market activities also has the potential to limit product innovation and availability, and the 
effects of added regulation tend to be largely regressive, disproportionally affecting poorer households and smaller firms (Chambers et al., 2019). However, several aspects suggest that these policies may be worth considering. First, consumer confusion about nutritional content is particularly pernicious as the plant-based alternatives are not good substitutes in terms of protein and calcium. Plant-based milk alternatives are generally considered nutritionally inferior, making it possible that the spill-over effects of consumer confusion might warrant government intervention to prevent undernutrition (Chalupa-Krebzdak et al., 2018).

Additionally, it might be that alternative plant-based beverages are free-riding on the generic marketing expenditures of the dairy industry, which pays for programs such as the "Got Milk?" and milk moustache campaigns. Dairy farmers in the United States have long paid marketing and promotion check-off funds for generic advertising; for every 100 pounds $(45.36 \mathrm{~kg}$ or about 11.6 gallons) of milk sold, dairy farmers pay 15 cents for promotion (Nicholson and Kaiser, 2008). For an average-producing US cow, this amounts to about $\$ 36$ annually. With 9.3 million milk cows producing approximately 215 billion pounds (97.52 billion $\mathrm{kg}$ ), farmers pay between $\$ 320$ and $\$ 330$ million annually for promotion and education programs. The dairy industry argues that using the word "milk" to label alternative beverages conveys to consumers that plant-based alternatives are substitutes for dairy milk and adds to consumer confusion (NMPF, 2019).

Finally, milk production is heavily regulated at all levels from the farm through the processor, generating and supporting public trust of fluid milk in the United States. It might be that the reputation and goodwill generated by the term "milk" over the years is being exploited by the alternative beverages, bestowing legitimacy to plant-based alternatives as an equally safe and nutritious substitute product. This rationale suggests that consumers might be less likely to use plant-based substitutes for coffee and cereal if the word "milk" was removed. However, the market segments in this study suggest that many households are choosing dairy and plant-based milk.

Like all research, this particular study has limitations. This research focused on general US milk consumption patterns and understanding clusters of household milk consumption. This research did not establish causal relationships between household socioeconomic demographics and beverage milk demand. Future research should delve into milk consumption and substitution patterns and examine the role of the word "milk" on US labels and consumer demand. Further analysis and understanding of US milk demand are warranted.

\section{CONCLUSIONS}

This research examined dairy milk and plant-based beverage consumption in the United States using a survey. Long-term trends of declining beverage milk consumption have been exacerbated in recent years by increasing consumption of plant-based beverages. Three consumption clusters for US households were identified using an online survey. The largest cluster, dairy households, comprising $61.6 \%$ of households, consumed dairy milk with some regularity and little or no plant-based beverages. A second cluster, flexitarian households, frequently consumed many types of beverages, including dairy milk and plant-based beverages. Flexitarian consumers comprised $15.6 \%$ of households. The final cluster, plant-based households, consumed almost exclusively plant-based beverages. This cluster comprised $22.8 \%$ of households. Flexitarian households were larger, more likely to include young children, more likely to include a vegetarian or vegan, and more liberal than traditional dairy-consuming households. The flexitarian and plant-based household clusters were willing to substitute plant-based beverages for dairy milk for almost all consumption uses.

\section{REFERENCES}

Atabek, Ü., and G. Şendur Atabek. 2019. Consumer perceptions towards dairy products: Effects of mass media. Online J. Commun. Media Technol. 9:1-15. https://doi.org/10.29333/ojcmt/5762.

Bir, C., N. O. Widmar, C. A. Wolf, and M. S. Delgado. 2019. Traditional attributes moo-ve over for some consumer segments: Relative ranking of fluid milk attributes. Appetite 134:162-171. https: //doi.org/10.1016/j.appet.2018.12.007.

Bus, A. E., and A. Worsley. 2003a. Consumers' sensory and nutritional perceptions of three types of milk. Public Health Nutr. 6:201-208. https://doi.org/10.1079/PHN2002417.

Bus, A. M., and A. Worsley. 2003b. Consumers' health perceptions of three types of milk: A survey in Australia. Appetite 40:93-100. https://doi.org/10.1016/S0195-6663(03)00004-7.

Capps, O., G. W. Williams, and V. Salin. 2016. Quantitative Evaluation of the Effectiveness of Marketing and Promotion Activities by the Milk Processor Education Program, Dairy Management, Inc., and Qualified Programs. Report. USDA, Washington, DC.

Chalupa-Krebzdak, S., C. J. Long, and B. M. Bohrer. 2018. Nutrient density and nutritional value of milk and plant-based milk alternatives. Int. Dairy J. 87:84-92. https://doi.org/10.1016/j.idairyj 2018.07.018.

Chambers, D., C. A. Collins, and A. Krause. 2019. How do federal regulations affect consumer prices? An analysis of the regressive effects of regulation. Public Choice 180:57-90. https://doi.org/10 $.1007 / \mathrm{s} 11127-017-0479-\mathrm{z}$.

Finnell, K. J., and R. John. 2017. Research to understand milk consumption behaviors in a food-insecure low-income SNAP population in the U.S. Beverages 3:46-58. https://doi.org/10.3390/ beverages3030046.

Gottlieb, S. 2018. Statement from FDA Commissioner Scott Gottlieb, M.D., on the process FDA is undertaking for reviewing and modernizing the agency's standards of identity for dairy products. Accessed Apr. 6, 2020. https://www.fda.gov/news-events/press -announcements/statement-fda-commissioner-scott-gottlieb-md -process-fda-undertaking-reviewing-and-modernizing. 
Harwood, W. S., and M. A. Drake. 2018. Identification and characterization of fluid milk consumer groups. J. Dairy Sci. 101:8860-8874. https://doi.org/10.3168/jds.2018-14855.

Irfan, U. 2018. "Fake milk": Why the dairy industry is boiling over plant-based milks. Accessed Apr. 11, 2020. https://www.vox.com/ 2018/8/31/17760738/almond-milk-dairy-soy-oat-labeling-fda.

Karlin, S. 2019. Is "cauliflower rice" misleading? "Truth in labeling" bill for veggies nears governor's desk. Accessed Apr. 11, 2020. https: //www.theadvocate.com/baton_rouge/news/politics/legislature/ article_b36be194-8621-11e9-b7c9-5b8506770731.html.

Malone, T., and J. L. Lusk. 2018. If you brew it, who will come? Market segments in the U.S. beer market. Agribusiness Int. J. 34:204-221.

McCarthy, K. S., M. Parker, A. Ameerally, S. L. Drake, and M. A. Drake. 2017. Drivers of choice for fluid milk versus plant-based alternatives: What are consumer perceptions of fluid milk? J. Dairy Sci. 100:6125-6138. https://doi.org/10.3168/jds.2016-12519.

Mercer, M. 2020. Stop milking it, dairy farmers tell plant-based competitors. Accessed Apr. 6, 2020. https://www.theeagle.com/ news/national/stop-milking-it-dairy-farmers-tell-plant-based -competitors/article_10365e0f-2b77-583d-a2ce-e326680f93c5.html.

Mintel. 2018. Report: Dairy and non-dairy milk-US-September 2018. Mintel, London, UK.

Naylor, T. 2018. Ditch the almond milk: Why everything you know about sustainable eating is probably wrong. Accessed May 7, 2020. https://www.theguardian.com/food/2018/sep/05/ditch-the -almond-milk-why-everything-you-know-about-sustainable-eating -is-probably-wrong.

Nicholson, C. F., and H. M. Kaiser. 2008. Dynamic market impacts of generic dairy advertising. J. Bus. Res. 61:1125-1135. https://doi .org/10.1016/j.jbusres.2007.11.011.

NMPF (National Milk Producers Federation). 2019. Survey: Only 1-in5 consumers think plant-based imitators should be called milk. Accessed Apr. 6, 2020. https://www.nmpf.org/survey-only-1-in-5 -consumers-think-plant-based-imitators-should-be-called-milk/.

Préjet, J. 2018. Comparing consumer perceptions of the health value of dairy milk and plant-based dairy milk alternatives. MS Thesis. University of Manitoba, Winnipeg, MB, Canada.

Schlecht, S., and A. Spiller. 2012. A latent class cluster analysis of farmers' attitudes towards contract design in the dairy industry. Agribusiness Int. J. 28:121-134.
Sibilla, N. 2019. FDA crackdown on calling almond milk "milk" could violate the first amendment. Accessed Feb. 1, 2020. https: //www.forbes.com/sites/nicksibilla/2019/01/31/fda-crackdown -on-calling-almond-milk-milk-could-violate-the-first-amendment/ \#5cae8c547b70.

Stewart, H., D. Dong, and A. Carlson. 2013. Why are Americans consuming less fluid milk? A look at intergenerational differences in intake frequency. USDA Economic Research Report No. 149. Accessed Apr. 6, 2020. https://www.ers.usda.gov/webdocs/ publications $/ 45073 / 37651 \_$err149.pdf? $v=41423$.

Sullivan. E. 2018. What's meat, anyway? Missouri label law says it comes from an animal; some disagree. Accessed May 7, 2019. https://www.npr.org/2018/08/29/642937901/whats-meat-anyway -missouri-label-law-says-it-comes-from-an-animal-some-disagree.

Teicholz, N. 2014. The Big Fat Surprise: Why Butter, Meat and Cheese Belong in a Healthy Diet. Simon and Schuster, New York, NY.

US Census Bureau. 2018. Annual estimates of the resident population for selected age groups by sex for the United States, states, counties, and Puerto Rico Commonwealth and Municipios: April 1, 2010 to July 1, 2018. Accessed Apr. 6, 2020. https://data .census.gov/cedsci/table? $q=$ PEPPOP2019.PEPANNRES\&tid= PEPPOP2019.PEPANNRES\&hidePreview $=$ true.

US FDA (US Food and Drug Administration). 2019. Code of Federal Regulations Title 21. Chapter 1, Subchapter B, Part 133.3a. Accessed Apr. 6, 2020. https://www.accessdata.fda.gov/scripts/ cdrh/cfdocs/cfcfr/CFRSearch.cfm?fr=133.3.

USDA ERS (USDA Economic Research Service). 2020. Dairy data. Accessed Apr. 6, 2020. https://www.ers.usda.gov/data-products/ dairy-data.

Whitmer, C. 2019. Consumers understand that almonds don't lactate. Accessed Apr. 6, 2020. https://thehill.com/opinion/healthcare/ 451870-consumers-understand-that-almonds-dont-lactate.

Wolf, C. A., G. T. Tonsor, and N. J. Olynk. 2011. Understanding US consumer demand for milk production attributes. J. Agric. Resour. Econ. 36:326-342.

\section{ORCIDS}

Christopher A. Wolf @ https://orcid.org/0000-0003-4181-285X 